\title{
The association between BDNF Val66Met polymorphism and emotional symptoms after mild traumatic brain injury
}

\author{
Yu-Jia Wang ${ }^{1,2}$, Kai-Yun Chen ${ }^{1}$, Li-Na Kuo ${ }^{2,4}$, Wen-Chang Wang ${ }^{3}$, Yu-Wen Hsu ${ }^{5}$, Henry Sung-Ching Wong ${ }^{4}$, \\ Chien-Min Lin ${ }^{6}$, Kuo-Hsing Liao ${ }^{7}$, Yan-Feng Zhang ${ }^{8}$, Yung-Hsiao Chiang ${ }^{1,9^{*}}$ and Wei-Chiao Chang ${ }^{1,2,4,10,11^{*}}$
}

\begin{abstract}
Background: Brain-derived neurotrophic factor (BDNF) is one of the most abundant neurotrophins in the adult brain, and it plays important roles in modulating synaptic plasticity and synaptogenesis. This study attempted to elucidate the role of the BDNF variant rs6265 in emotional symptoms following mild traumatic brain injury (mTBI).

Methods: To investigate the association between BDNF Val66Met polymorphism (rs6265) and emotional symptoms in mTBI patients, we recruited 192 mTBI patients and evaluated their Beck Anxiety Inventory (BAI) and Beck Depression Inventory (BDI) scores in the first and sixth week after mTBI.

Results: The patients carrying the T allele of rs6265 had significantly higher BAl scores in the first week following mTBI. In addition, the patients carrying the T allele also showed higher scores of BDI in the first week. In the gender-specific subgroup analysis, the male patients carrying the T allele of rs6265 had higher scores of both BAI and BDI in the first and sixth week. Meanwhile, female patients carrying the T allele also had significantly higher scores of BDI in the first week following mTBl.
\end{abstract}

Conclusions: This study provides evidence for the association between the BDNF variant rs6265 and emotional symptoms following mTBl.

Keywords: Mild traumatic brain injury, Genetic polymorphism, Brain-derived neurotrophic factor, Anxiety, Depression

\section{Background}

Traumatic brain injury (TBI) is a leading cause of death and disability worldwide. The rates of TBI-related emergency department (ED) visits have been estimated to be increased by $70 \%$ over the past decade. In 2010, The Center for Disease Control and Prevention (CDC) reported that 2.5 million ED visits, hospitalizations, and deaths are associated with TBI in the United States. Additionally, current data indicate that about $3.2 \sim 5.3$ million persons in the United States are living with disabilities related to TBI $[1,2]$. TBI is an alteration of the brain's normal functioning, caused by a blow or external force to the head [3]. The most common causes of TBI include falls, traffic accidents, and assaults [4]. The

\footnotetext{
*Correspondence: ychiang@tmu.edu.tw; wcc@tmu.edu.tw

${ }^{1}$ Ph.D. Program for Neural Regenerative Medicine, College of Medical Science and Technology, Taipei Medical University, Taipei, Taiwan

Full list of author information is available at the end of the article
}

severity of TBI can be categorized based on the clinical presentation using the Glasgow Coma Scale (GCS), which is to assess three components of the neurologic functions: eye opening, verbal response, and motor response. Patients with overall scores of $3 \sim 8$ are classified as severe, those of $9 \sim 12$ are moderate, and those of $13 \sim 15$ are mild [5]. More than $75 \%$ of TBI cases are classified as mild TBI (mTBI) [6]. Although most mTBI cases are expected to fully recover within days to months, some patients still show persistent cognitive, physical, and emotional impairments. Furthermore, psychological and neurological disorders can also develop after an mTBI (e.g., depression, epilepsy, and insomnia). These chronic health effects of mTBI may cause difficulties returning to one's routine, daily activities, and work $[7,8]$.

The molecular repair mechanisms following brain injury are complex and multifactorial processes. Recently, researchers have focused on genetic factors that 
influence the TBI pathophysiology. For example, apolipoprotein $\mathrm{E}(A P O E)$, the gene located at position $\mathrm{q} 13.2$ on chromosome 19 is one of the most widely studied genetic factors for posttraumatic recovery [9]. ApoE is a plasma lipoprotein that maintains the integrity of neuronal membranes, and functions in neuronal repair and remodeling. Patients with $A P O E 4$ allele showed a higher risk of poor clinical outcomes following TBI [9-11]. Genetic variants of monoamine oxidase A $(M A O-A)$, interleukin 6 (IL-6), and catechol-O-methyltransferase (COMT) have also been studied [12-15].

Brain-derived neurotrophic factor (BDNF) is one of the most abundant neurotrophins in the central nervous system, and plays important roles in neuronal growth, differentiation, apoptosis, and synaptic plasticity [1618]. BDNF has been found to associate with cognitive function, personality development, psychiatric disorders, and neurodegenerative diseases [19-21]. Accumulating evidence indicates the involvement of BDNF in the pathophysiology of mood disorders [22-25]. Previous animal study showed that BDNF knockdown in the hippocampal subregion produced depression-like behaviors in rats [26]. In addition, the decreased BDNF signaling was observed in the subgenual anterior cingulate cortex in major depressive patients [27]. Furthermore, the recent meta-analysis study revealed that the BDNF blood level had significantly difference between the healthy subjects and patients with major depression [28].

The single nucleotide polymorphism (SNP) rs6265 located in the coding region of the BDNF gene is one of the most important SNPs. A change of amino acids from valine to methionine (Val66Met) alters the intracellular tracking of pro-BDNF and affects the secretion and neuroplastic effect of the mature BDNF protein $[29,30]$. Growing evidence highlights the role of rs6265 in psychiatric disorders, suicidal behavior and the pharmacologic treatment responses [31-34]. Previous studies supported the important role of the rs6265 polymorphism in cognitive performance and executive function following TBI $[35,36]$. However, the role of rs6265 in TBI-related emotional symptoms has not been characterized. We therefore hypothesized that rs6265 might also be associated with emotional symptoms following TBI. Self-reporting questionnaires (Beck Anxiety Inventory (BAI) and Beck Depression Inventory (BDI)) in the first and sixth week were collected to evaluate emotional symptoms. Previous studies found a gender-specific influence of $B D N F$ on mood disorders [37-40]. Therefore, we wished to conduct a gender-specific subgroup analysis to find out whether the association between the $B D N F$ variant rs6265 and emotional symptoms following mTBI is affected by gender.

\section{Methods}

\section{Subject recruitment}

Patients aged $\geq 20$ years who had been diagnosed with mTBI in the emergency department were recruited from three Taipei Medical University (TMU) affiliated hospitals, including TMU Hospital, Wan Fang Medical Center, and Shuang Ho Hospital. The diagnosis of mTBI was determined according to diagnostic criteria established by the American Congress of Rehabilitation Medicine, a GCS score of $13 \sim 15$, and a time of loss of consciousness of $<30 \mathrm{~min}$. This study was approved by TMU Joint Institutional Review Board, with the requirement to have written informed consent.

\section{Self-reporting questionnaires}

Emotional symptoms of included patients were evaluated in the first- and sixth-week visits after a diagnosis of mTBI. The BAI and BDI were completed by patients to respectively evaluate anxiety and depression symptoms. The BAI is a 21-item self-reporting inventory to assess the severity of anxiety symptoms. Each item is rated on a 4-point scale from 0 (not at all) to 3 (severely). Total scores range 0 63, with $0 \sim 7$ indicating minimal anxiety, $8 \sim 15$ mild anxiety, $16 \sim 25$ moderate anxiety, and $26 \sim 63$ severe anxiety [41]. The BAI has a high internal consistency (Cronbach's $\alpha=0.92$ ) and a test-retest reliability over 1 week of 0.75 [41]. BDI, a 21item self-reporting inventory, is to measure cognitive, behavioral, and physiological symptoms associated with depression. Responses are made on a 4-point scale from 0 to 3 , with total scores ranging $0 \sim 63$. Cutoff ranges are as follows: $0 \sim 9$ indicates normal, $10 \sim 18$ mild depression, $19 \sim 29$ moderate depression, and $30 \sim 63$ severe depression. Cronbach's $\alpha$ has been reported as 0.92 , and the test-retest correlation over 1 week as 0.93 [42, 43].

\section{DNA extraction}

DNA was extracted from the whole-blood samples of mTBI patients. Blood cells were first treated with 0.5\% sodium dodecyl sulfate (SDS) lysis buffer, and then a proteinase $\mathrm{K}$ solution $(1 \mathrm{mg} / \mathrm{mL})$ was used for $4 \mathrm{~h}$ at $60{ }^{\circ} \mathrm{C}$ to digest the nuclear proteins. Total DNA was harvested using a Gentra extraction kit (Qiagen, Valencia, California, USA) followed by $70 \%$ alcohol precipitation.

\section{Genotyping of BDNF rs6265}

Genotyping for BDNF rs6265 (Val66Met) polymorphism was performed using the TaqMan Allelic Discrimination Assay (Applied Biosystems, Foster City, California, USA). A polymerase chain reaction (PCR) used a 96-well microplate with the ABI 9700 Thermal Cycler (Applied Biosystems, Foster City, California, USA). The thermal cycle conditions of the PCR were set as follows: denaturing at $95{ }^{\circ} \mathrm{C}$ for $10 \mathrm{~min}$, followed by 40 cycles of 
denaturing at $95{ }^{\circ} \mathrm{C}$ for $15 \mathrm{~s}$, and annealing and extension at $60{ }^{\circ} \mathrm{C}$ for $1 \mathrm{~min}$. After the PCR, StepOne software (version 2.2.2, Applied Biosystems, Foster City, California, USA) was used to detect and analyze the fluorescence intensity.

\section{Statistical analysis}

R 3.2.0 (http://www.r-project.org) was used for the statistical analyses. A Linear regression model was used for patient characteristics to define the possible confounding factors, including age, gender, Glasgow Coma Scale (GCS), Extended Glasgow Outcome Scale (GOSE), mechanism of injury and current medication use. We analyzed the magnitude of the association between the different genotypes of rs6265 and BAI, BDI scores through a likelihood ratio test in four models (including codominant, dominant, recessive and log-additive model) that implemented in SNPassoc package. BAI and BDI scores of each genotype group were presented with mean \pm standard error (s.e.). Patients with missing or incomplete data of BAI, BDI and baseline covariates were excluded from the analyses. Statistical significance was considered at $p<0.05$.

\section{Results}

\section{Demographics of mTBI patients}

In total, we recruited 192 study patients with mTBI to evaluate the emotional symptoms in the first and sixth week after brain injury. Demographic characteristics are summarized in Table 1. Patients age ranged $20 \sim 83$ years, with a mean age of 39.3 years. Females accounted for $68.2 \%(131 / 192)$ of total recruited patients. The causes of brain injury were mainly from traffic accidents 55.7\% (107/192), falls 30.7\% (59/192), and sports-related injuries or workplace accidents $13.5 \%$ (26/192). However, some patients were lost to follow-up after the first week's visit. In total, 103 (54\%) study patients had attended the sixth-week's visit and completed the assessment.

\section{Confounding factors for emotional symptoms following mTBI}

The correlation between patient characteristics and BAI, BDI scores were analyzed using linear regression model to evaluate potential confounding factors. BAI and BDI scores showed moderate correlation with each other in the first and sixth week following mTBI (Additional file 1: Figure S1 and S2). The covariates including GCS, GOSE, injuries caused by traffic accidents or falls, and current antidepressant or hypnotic medication use were correlated with BAI and BDI (Additional file 1: Table S1). These covariates were adjusted for potential confounding effects.
Table 1 Characteristics of patients with mild traumatic brain injury (mTBI) in the first and sixth week

\begin{tabular}{|c|c|c|}
\hline Patient characteristic & $\begin{array}{l}\text { First week visit } \\
(n=192)\end{array}$ & $\begin{array}{l}\text { Sixth week visit } \\
(n=103)\end{array}$ \\
\hline \multicolumn{3}{|l|}{ Gender, no. (\%) } \\
\hline Female & $131(68.2)$ & $67(65.0)$ \\
\hline Male & $61(31.8)$ & $36(35.0)$ \\
\hline Age, years $^{a}$ & $39.3 \pm 15.4$ & $40.4 \pm 15.6$ \\
\hline \multicolumn{3}{|l|}{ Injury mechanism, no. (\%) } \\
\hline Traffic accidents & $107(55.7)$ & $47(45.6)$ \\
\hline Falls & $59(30.7)$ & $40(38.8)$ \\
\hline Other & $26(13.5)$ & $16(15.5)$ \\
\hline GCS score at $E D^{b}$ & $15[15-15]$ & 15 [15-15] \\
\hline GOSE $^{\mathrm{b}}$ & $7[6-8]$ & $7[6-8]$ \\
\hline BAl score ${ }^{a}$ & $8.91 \pm 9.32$ & $7.51 \pm 8.37$ \\
\hline BDI score ${ }^{a}$ & $8.91 \pm 7.94$ & $8.09 \pm 8.04$ \\
\hline Antidepressant medication use & $3(1.6)$ & $2(1.9)$ \\
\hline Anti-anxiety medication use & $5(2.6)$ & $4(3.9)$ \\
\hline Hypnotic medication use & $8(4.2)$ & $4(3.9)$ \\
\hline
\end{tabular}

IQR interquartile range, GCS Glasgow Coma Score, ED Emergency department, GOSE Extended Glasgow Outcome Scale, BAI Beck Anxiety Inventory, BDI Beck Depression Inventory

${ }^{a}$ Mean \pm standard deviation

${ }^{\mathrm{b}}$ Median [IQR]

Association between BAI scores and the rs6265 polymorphism in the first week following $\mathrm{mTBI}$

First, we examined whether rs6265 of the BDNF gene was associated with BAI scores. This questionnaire was completed in the first and sixth week after mTBI. Table 2 shows BAI scores among the three genotypes in the first week (TT genotype: $11.41 \pm 1.88$; CT genotype: $9.67 \pm 1.20$; $\mathrm{CC}$ genotype: $6.39 \pm 1.35$ ). Patients carrying the $\mathrm{T}$ allele showed significantly higher scores of BAI through Logadditive model $(p=0.028)$ in the first week. In addition, the male patients carrying the $\mathrm{T}$ allele also showed higher BAI scores in Log-additive model $(p=0.01)$. However, the BAI scores were no differences between the three genotypes in female patients.

\section{Association between BAI scores and the rs6265 polymorphism in the sixth week following $\mathrm{mTBI}$}

BAI scores among the three genotypes in the sixth week (TT genotype: $6.64 \pm 2.20$; CT genotype: $7.85 \pm 1.36$; CC genotype: $8.21 \pm 1.96$ ) are shown in Table 3. There were no significant differences among the three genotypes. However, the male patients carrying the $\mathrm{T}$ allele still showed significantly higher BAI scores in Log-additive model $(p=0.038)$.

\section{Association between BDI scores and the rs6265} polymorphism in the first week following $\mathrm{mTBI}$ Depressive symptoms were measured by BDI scores in the first week and sixth week after brain injury. BDI 
Table 2 Association analysis between rs6265 polymorphism and BAI scores in the first week following mTBI

\begin{tabular}{|c|c|c|c|c|c|c|}
\hline Genotype & Sample no. (\%) & BAl score ${ }^{a}$ & Codominant $p$ value & Dominant $p$ value & Recessive $p$ value & Log-additive $p$ value \\
\hline \multicolumn{7}{|c|}{ Total $(n=184)$} \\
\hline$\pi$ & $40(21.7)$ & $11.41 \pm 1.88$ & 0.083 & 0.117 & $0.043^{*}$ & $0.028^{*}$ \\
\hline $\mathrm{CT}$ & $89(48.4)$ & $9.67 \pm 1.20$ & & & & \\
\hline CC & 55 (29.9) & $6.39 \pm 1.35$ & & & & \\
\hline \multicolumn{7}{|c|}{ Male $(n=57)$} \\
\hline$\pi$ & $14(24.6)$ & $8.80 \pm 1.97$ & $0.037^{*}$ & 0.054 & $0.022^{*}$ & $0.010^{*}$ \\
\hline $\mathrm{CT}$ & $24(42.1)$ & $6.15 \pm 2.52$ & & & & \\
\hline CC & 19 (33.3) & $4.36 \pm 1.56$ & & & & \\
\hline \multicolumn{7}{|c|}{ Female $(n=127)$} \\
\hline$\pi$ & $26(20.5)$ & $12.94 \pm 2.72$ & 0.229 & 0.400 & 0.091 & 0.119 \\
\hline $\mathrm{CT}$ & $65(51.2)$ & $10.81 \pm 1.34$ & & & & \\
\hline $\mathrm{CC}$ & $36(28.3)$ & $7.50 \pm 1.89$ & & & & \\
\hline
\end{tabular}

${ }^{a}$ Mean \pm standard error (s.e.). The $p$ value was adjusted for GCS, GOSE, injury mechanism, antidepressant medication use and hypnotic medication use. ${ }^{*} p<0.05$ is labeled in bold

scores among the three genotypes in the first week (TT genotype: $12.56 \pm 1.62$; CT genotype: $8.83 \pm 0.97$; CC genotype: $7.06 \pm 1.72$ ) are shown in Table 4. Patients carrying the $\mathrm{T}$ allele showed higher scores of BDI $(p=0.006)$. In the gender-specific analysis, the female patients carrying the $\mathrm{T}$ allele had significantly higher BDI scores in the first week using log-additive model $(p=0.015)$. Meanwhile, the male patients carrying the $\mathrm{T}$ allele also showed higher BDI scores $(p=0.029)$.

\section{Association between BDI scores and the rs6265} polymorphism in the sixth week following $\mathrm{mTBI}$

BDI scores among the three genotypes in the sixth week (TT genotype: $11.55 \pm 2.90$; CT genotype: $9.30 \pm 1.46$; $\mathrm{CC}$ genotype: $6.83 \pm 1.79$ ) are shown in Table 5 . There were no significant differences among the three genotypes.
However, the male patients carrying the $\mathrm{T}$ allele showed significantly higher BDI scores in the sixth week $(p=0.021)$.

\section{Discussion}

In this study, we evaluated the role of genetic polymorphism of $B D N F$ (rs6265) in the emotional symptoms in patients with mTBI. We recruited 192 mTBI patients to evaluate anxiety and depressive symptoms using the BAI and BDI scores in the first and sixth week after mTBI. Results from BDI scores showed a strong association between the rs6265 polymorphism and depressive symptoms following mTBI in the first week. Patients carrying the $\mathrm{T}$ allele had more depressive symptoms than patients carrying the $\mathrm{C}$ allele. In addition, BAI scores revealed that patients carrying the $\mathrm{T}$ allele also had more

Table 3 Association analysis between rs6265 polymorphism and BAl scores in the sixth week following mTBI

\begin{tabular}{|c|c|c|c|c|c|c|}
\hline Genotype & Sample no. (\%) & BAl score ${ }^{a}$ & Codominant $p$ value & Dominant $p$ value & Recessive $p$ value & Log-additive $p$ value \\
\hline \multicolumn{7}{|c|}{ Total $(n=103)$} \\
\hline$\pi$ & $16(15.5)$ & $6.64 \pm 2.20$ & 0.578 & 0.300 & 0.850 & 0.423 \\
\hline $\mathrm{CT}$ & $55(53.4)$ & $7.85 \pm 1.36$ & & & & \\
\hline CC & $32(31.1)$ & $8.21 \pm 1.96$ & & & & \\
\hline \multicolumn{7}{|c|}{ Male $(n=36)$} \\
\hline$\pi$ & $5(13.9)$ & $10.33 \pm 6.57$ & 0.060 & 0.225 & $0.019 *$ & $0.038^{*}$ \\
\hline $\mathrm{CT}$ & $20(55.6)$ & $6.36 \pm 2.33$ & & & & \\
\hline CC & $11(30.6)$ & $2.38 \pm 1.00$ & & & & \\
\hline \multicolumn{7}{|c|}{ Female $(n=67)$} \\
\hline$\pi$ & $11(16.4)$ & $5.25 \pm 1.96$ & 0.166 & 0.082 & 0.193 & 0.059 \\
\hline $\mathrm{CT}$ & $35(52.2)$ & $8.59 \pm 1.69$ & & & & \\
\hline CC & $21(31.3)$ & $11.13 \pm 2.62$ & & & & \\
\hline
\end{tabular}

${ }^{a}$ Mean \pm standard error (s.e.). The $p$ value was adjusted for GCS, GOSE, injury mechanism, antidepressant medication use and hypnotic medication use. ${ }^{*} p<0.05$ is labeled in bold 
Table 4 Association analysis between rs6265 polymorphism and BDI scores in the first week following mTBI

\begin{tabular}{|c|c|c|c|c|c|c|}
\hline Genotype & Sample no. (\%) & BDI score ${ }^{a}$ & Codominant $p$ value & Dominant $p$ value & Recessive $p$ value & Log-additive $p$ value \\
\hline \multicolumn{7}{|c|}{ Total $(n=186)$} \\
\hline$\pi$ & $41(22.0)$ & $12.56 \pm 1.62$ & $0.009^{* *}$ & 0.144 & $0.002^{* *}$ & $0.006^{* *}$ \\
\hline $\mathrm{CT}$ & $89(47.8)$ & $8.83 \pm 0.97$ & & & & \\
\hline CC & $56(30.1)$ & $7.06 \pm 1.72$ & & & & \\
\hline \multicolumn{7}{|c|}{ Male $(n=60)$} \\
\hline$\pi$ & $15(25.0)$ & $8.10 \pm 1.22$ & 0.093 & 0.050 & 0.107 & $0.029 *$ \\
\hline $\mathrm{CT}$ & $26(43.3)$ & $8.50 \pm 2.09$ & & & & \\
\hline CC & $19(31.7)$ & $6.36 \pm 3.15$ & & & & \\
\hline \multicolumn{7}{|c|}{ Female $(n=126)$} \\
\hline$\pi$ & $26(20.6)$ & $15.18 \pm 2.25$ & $0.007^{* *}$ & 0.381 & $0.002^{* *}$ & $0.015^{*}$ \\
\hline $\mathrm{CT}$ & $63(50.0)$ & $8.95 \pm 1.10$ & & & & \\
\hline CC & $37(29.4)$ & $7.43 \pm 2.09$ & & & & \\
\hline
\end{tabular}

${ }^{a}$ Mean \pm standard error (s.e.). The $p$ value was adjusted for GCS, GOSE, injury mechanism, antidepressant medication use and hypnotic medication use. ${ }^{*} 0.01 \leq p<0.05$ is labeled in bold. ${ }^{* *} p<0.01$ is labeled in bold

anxiety symptoms than patients carrying the $\mathrm{C}$ allele in the first week. However, the influence of rs6265 on anxiety and depressive symptoms in the sixth week was not observed in our study.

The gender-specific subgroup analyses revealed that the male patients carrying the $\mathrm{T}$ allele of rs6265 had higher scores of BAI and BDI in the both first and sixth week. The female patients carrying the $\mathrm{T}$ allele had significantly higher scores of BDI in the first week, whereas the difference was not shown in the sixth week. We speculate that this gender differences may be explained by the interaction between sex steroid hormones and BDNF following brain injury. Accumulating evidence indicates that estrogen regulates the $B D N F$ expression through many several mechanisms such as methylation or directly bind to the $B D N F$ gene via estrogen receptor $[40,44-46]$.
Our study reported an important role of BDNF in the emotional symptoms after mTBI. Indeed, recent genetic association studies indicated the correlations between rs6265 of $B D N F$ and cognitive outcomes after mTBI [35, 36, 47]. The mechanisms of depressive disorders may be due to aberrant regulation of neuronal plasticity, including neurotrophic factors that regulate neurogenesis in the hippocampus and limbic system [19]. Previous animal studies also showed that deletion of BDNF increases susceptibility to depressive effects [48, 49], and hippocampus-specific knockdown of BDNF produces several depressive-like behaviors in rats [26]. Meanwhile, recent clinical studies indicated that BDNF might decrease the hippocampal volume and increase the risk of developing depression in those exposed to environmental stress or trauma [50-53]. These evidence

Table 5 Association analysis between rs6265 polymorphism and BDI scores in the sixth week following mTBI

\begin{tabular}{|c|c|c|c|c|c|c|}
\hline Genotype & Sample no. (\%) & BDI score ${ }^{a}$ & Codominant $p$ value & Dominant $p$ value & Recessive $p$ value & Log-additive $p$ value \\
\hline \multicolumn{7}{|c|}{ Total $(n=103)$} \\
\hline$\Pi$ & $16(15.5)$ & $11.55 \pm 2.90$ & 0.327 & 0.382 & 0.148 & 0.170 \\
\hline $\mathrm{CT}$ & $55(53.4)$ & $9.30 \pm 1.46$ & & & & \\
\hline $\mathrm{CC}$ & $32(31.1)$ & $6.83 \pm 1.79$ & & & & \\
\hline \multicolumn{7}{|c|}{ Male $(n=36)$} \\
\hline$\pi$ & $5(13.9)$ & $14.00 \pm 7.02$ & $0.032 *$ & 0.174 & $0.010^{*}$ & $0.021 *$ \\
\hline $\mathrm{CT}$ & $20(55.6)$ & $6.91 \pm 2.56$ & & & & \\
\hline $\mathrm{CC}$ & $11(30.6)$ & $2.13 \pm 0.61$ & & & & \\
\hline \multicolumn{7}{|c|}{ Female $(n=67)$} \\
\hline$\pi$ & $11(16.4)$ & $10.63 \pm 3.29$ & 0.878 & 0.620 & 0.767 & 0.621 \\
\hline CT & $35(52.2)$ & $10.50 \pm 1.76$ & & & & \\
\hline CC & $21(31.3)$ & $9.19 \pm 2.49$ & & & & \\
\hline
\end{tabular}

${ }^{a}$ Mean \pm standard error (s.e.). The $p$ value was adjusted for GCS, GOSE, injury mechanism, antidepressant medication use and hypnotic medication use. ${ }^{*} p<0.05$ is labeled in bold 
provide possible mechanisms for the findings in our present study.

There are several limitations to our study. First, the small sample size and short study duration may limit our findings. Second, other genetic polymorphisms of the $B D N F$ gene were not investigated in the present study. Conducting direct $B D N F$ sequencing may be useful for identifying new SNPs in the $B D N F$ gene and clarifying the effects of $B D N F$ polymorphisms in various outcomes of mTBI. This study provides evidence for the correlation between genetic polymorphism of rs6265 of BDNF and emotional symptoms in the early phase after mTBI. Since our study duration range from one to sixth weeks, further studies with longer duration of follow-up are needed to elucidate the long term effects of the rs6265 polymorphism on emotional symptoms following mTBI.

\section{Conclusions}

Our study provides evidence for the correlation between the $B D N F$ variant rs6265 and emotional symptoms in the early phase after mTBI.

\section{Additional file}

Additional file 1: Table S1. The confounding factors for BAI and BDI scores. Figure S1. Correlation between BAI and BDI score in the first week ( $p$-value <0.001; Adjusted $R^{2}=0.3101$ ). Figure S2. Correlation between BAl and BDI score in the sixth week ( $p$-value $<0.001$; Adjusted $\left.R^{2}=0.5013\right)$. (DOCX $\left.175 \mathrm{~kb}\right)$

\section{Abbreviations \\ APOE: Apolipoprotein E; BAl: Beck anxiety inventory; BDI: Beck depression inventory; BDNF: Brain-derived neurotrophic factor; CDC: Center for disease control and prevention; COMT: Catechol-O-methyltransferase; ED: Emergency department; GCS: Glasgow coma scale; GOSE: Extended glasgow outcome scale; IL-6: Interleukin 6; MAO-A: Monoamine oxidase A; mTBI: Mild traumatic brain injury; PCR: Polymerase chain reaction; SD: Standard deviation; SDS: Sodium dodecyl sulfate; SNP: Single nucleotide polymorphism; TBI: Traumatic brain injury}

\section{Acknowledgements}

We thank the Center for Neurotrauma and Neuroregeneration of Taipei Medical University for their assistance during the study. In addition, we greatly thank Mengtse Lee for improving the use of English in the revised manuscript.

\section{Funding}

This work was supported by grants from Ministry of Health and Welfare (MOHW103-TDU-B-212-113001), from Ministry of Science and Technology (MOST105-2628-B-038-001-MY4) and from National Health Research Institutes (06D1-MMMOHW08)

\section{Availability of data and materials}

The datasets used and/or analysed during the current study available from the corresponding author on reasonable request.

\section{Authors' contributions}

YJW: study concept and design; implementation of experiments; analysis and interpretation of data; drafting of the manuscript. KYC, CML, KHL: data acquisition; drafting of the manuscript. LNK, WCW, YFZ: analysis and interpretation of data; revising the manuscript critically for important intellectual content. YWH, HSCW: analysis and interpretation of data; drafting of the manuscript. YHC, WCC: study concept and design; drafting of the manuscript; supervising the work. All authors read and approved the final manuscript.

\section{Ethics approval and consent to participate}

This study was approved by Taipei Medical University - Joint Institutional Review Board (TMU-JIRB). Samples were collected from patients with written informed consent at three Taipei Medical University (TMU) affiliated hospitals.

\section{Consent for publication}

Not applicable.

\section{Competing interests}

The authors declare that they have no competing interests.

\section{Publisher's Note}

Springer Nature remains neutral with regard to jurisdictional claims in published maps and institutional affiliations.

\section{Author details}

${ }^{1}$ Ph.D. Program for Neural Regenerative Medicine, College of Medical Science and Technology, Taipei Medical University, Taipei, Taiwan. ${ }^{2}$ Department of Pharmacy, Wan Fang Hospital, Taipei Medical University, Taipei, Taiwan. ${ }^{3}$ Ph.D. Program for Translational Medicine, College of Medical Science and Technology, Taipei Medical University, Taipei, Taiwan. ${ }^{4}$ Department of Clinical Pharmacy, School of Pharmacy, Taipei Medical University, Taipei, Taiwan. ${ }^{5}$ Ph.D. Program for Translational Medicine, College of Medical Science and Technology, Taipei Medical University and Academia Sinica, Taipei, Taiwan. ${ }^{6}$ Department of Neurosurgery, Shuang Ho Hospital, Taipei Medical University, New Taipei City, Taiwan. ${ }^{7}$ Department of Neurosurgery, Wan Fang Hospital, Taipei Medical University, Taipei, Taiwan. ${ }^{8}$ HudsonAlpha Institute for Biotechnology, Huntsville, AL, USA. ${ }^{9}$ Division of Neurosurgery, Department of Surgery, Taipei Medical University Hospital, Taipei, Taiwan. ${ }^{10}$ Master Program for Clinical Pharmacogenomics and Pharmacoproteomics, School of Pharmacy, Taipei Medical University, Taipei, Taiwan. ${ }^{11}$ Center for Biomarkers and Biotech Drugs, Kaohsiung Medical University, Kaohsiung, Taiwan.

Received: 7 September 2017 Accepted: 22 December 2017

Published online: 22 January 2018

\section{References}

1. Korley FK, Kelen GD, Jones CM, Diaz-Arrastia R: Emergency Department Evaluation of Traumatic Brain Injury in the United States, 2009-2010. The Journal of head trauma rehabilitation 2015.

2. Coronado VG, Xu L, Basavaraju SV, McGuire LC, Wald MM, Faul MD, Guzman BR, Hemphill JD. Surveillance for traumatic brain injury-related deaths-United States, 1997-2007. Morb. Mortal. Wkly. Rep. Surveill. Summ. (Washington, DC : 2002). 2011;60(5):1-32.

3. Menon DK, Schwab K, Wright DW, Maas Al. Position statement: definition of traumatic brain injury. Arch Phys Med Rehabil. 2010;91(11):1637-40.

4. Coronado VG, MCGuire LC, Sarmiento K, Bell J, Lionbarger MR, Jones CD, Geller Al, Khoury N, Xu L. Trends in traumatic brain injury in the U.S. and the public health response: 1995-2009. J Saf Res. 2012;43(4):299-307.

5. Teasdale $G$, Jennett B. Assessment of coma and impaired consciousness. A practical scale. Lancet (London, England). 1974;2(7872):81-4.

6. McCauley SR, Wilde EA, Miller ER, Frisby ML, Garza HM, Varghese R, Levin HS, Robertson CS, McCarthy JJ. Preinjury resilience and mood as predictors of early outcome following mild traumatic brain injury. J Neurotrauma. 2013:30(8):642-52

7. Marshall S, Bayley M, McCullagh S, Velikonja D, Berrigan L, Ouchterlony D, Weegar K. Updated clinical practice guidelines for concussion/mild traumatic brain injury and persistent symptoms. Brain Inj. 2015;29(6):688-700.

8. Corrigan JD, Selassie AW, Orman JA. The epidemiology of traumatic brain injury. J Head Trauma Rehabil. 2010;25(2):72-80.

9. Chamelian $L$, Reis $M$, Feinstein $A$. Six-month recovery from mild to moderate traumatic brain injury: the role of APOE-epsilon4 allele. Brain J. Neurol. 2004;127(Pt 12):2621-8.

10. Zhou W, Xu D, Peng X, Zhang Q, Jia J, Crutcher KA. Meta-analysis of APOE4 allele and outcome after traumatic brain injury. J Neurotrauma. 2008:25(4):279-90.

11. Alexander S, Kerr ME, Kim Y, Kamboh MI, Beers SR, Conley YP. Apolipoprotein E4 allele presence and functional outcome after severe traumatic brain injury. J Neurotrauma. 2007;24(5):790-7.

12. Wilson $\mathrm{M}$, Montgomery $\mathrm{H}$. Impact of genetic factors on outcome from brain injury. Br J Anaesth. 2007;99(1):43-8. 
13. Dardiotis E, Fountas KN, Dardioti M, Xiromerisiou G, Kapsalaki E, Tasiou A, Hadjigeorgiou GM. Genetic association studies in patients with traumatic brain injury. Neurosurg Focus. 2010;28(1):E9.

14. Weaver SM, Chau A, Portelli JN, Grafman J. Genetic polymorphisms influence recovery from traumatic brain injury. The Neuroscientist : a review journal bringing neurobiology, neurology and psychiatry. 2012;18(6):631-44.

15. Diaz-Arrastia R, Baxter VK. Genetic factors in outcome after traumatic brain injury: what the human genome project can teach us about brain trauma. J Head Trauma Rehabil. 2006;21(4):361-74.

16. Webster MJ, Weickert CS, Herman MM, Kleinman JE. BDNF mRNA expression during postnatal development, maturation and aging of the human prefrontal cortex. Brain Res Dev Brain Res. 2002;139(2):139-50.

17. Cunha C, Brambilla R, Thomas KL. A simple role for BDNF in learning and memory? Front Mol Neurosci. 2010;3:1.

18. Nagahara AH, Tuszynski MH. Potential therapeutic uses of BDNF in neurological and psychiatric disorders. Nat Rev Drug Discov. 2011;10(3):209-19.

19. Balaratnasingam S, Janca A. Brain derived Neurotrophic factor: a novel neurotrophin involved in psychiatric and neurological disorders. Pharmacol Ther. 2012;134(1):116-24

20. Hariri AR, Goldberg TE, Mattay VS, Kolachana BS, Callicott JH, Egan MF, Weinberger DR. Brain-derived neurotrophic factor val66met polymorphism affects human memory-related hippocampal activity and predicts memory performance. J Neurosci Off J Soc Neurosci. 2003:23(17):6690-4.

21. Herbert J, Ban M, Brown GW, Harris TO, Ogilvie A, Uher R, Craig TK. Interaction between the BDNF gene Val/66/met polymorphism and morning cortisol levels as a predictor of depression in adult women. Br J Psychiatry J Ment Sci. 2012;201(4):313-9.

22. Jin HJ, Pei L, Li YN, Zheng H, Yang S, Wan Y, Mao L, Xia YP, He QW, Li M, et al. Alleviative effects of fluoxetine on depressive-like behaviors by epigenetic regulation of BDNF gene transcription in mouse model of post-stroke depression. Sci Rep. 2017;7(1):14926.

23. Jiang R, Babyak MA, Brummett BH, Siegler IC, Kuhn CM, Williams RB. Brain-derived neurotrophic factor (BDNF) Val66Met polymorphism interacts with gender to influence cortisol responses to mental stress. Psychoneuroendocrinology. 2017;79:13-9.

24. Li K, Shen S, Ji YT, Li XY, Zhang LS, Wang XD. Melatonin Augments the Effects of Fluoxetine on Depression-Like Behavior and Hippocampal BDNF-TrkB Signaling. Neurosci Bull. 2017. https://doi.org/10.1007/s12264-017-0189-z.

25. Caldieraro MA, McKee M, Leistner-Segal S, Vares EA, Kubaski F, Spanemberg L, Brusius-Facchin AC, Fleck MP, Mischoulon D. Val66Met polymorphism association with serum BDNF and inflammatory biomarkers in major depression. The world journal of biological psychiatry : the official journal of the World Federation of Societies of Biological Psychiatry. 2017. https://doi. org/10.1080/15622975.2017.1347713.

26. Taliaz D, Stall N, Dar DE, Zangen A. Knockdown of brain-derived neurotrophic factor in specific brain sites precipitates behaviors associated with depression and reduces neurogenesis. Mol Psychiatry. 2010;15(1):80-92.

27. Tripp A, Oh H, Guilloux JP, Martinowich K, Lewis DA, Sibille E. Brain-derived neurotrophic factor signaling and subgenual anterior cingulate cortex dysfunction in major depressive disorder. Am J Psychiatry. 2012;169(11):1194-202.

28. Brunoni AR, Lopes M, Fregni F. A systematic review and meta-analysis of clinical studies on major depression and BDNF levels: implications for the role of neuroplasticity in depression. Int J Neuropsychopharmacol. 2008;11(8):1169-80.

29. Boulle F, van den Hove DL, Jakob SB, Rutten BP, Hamon M, van Os J, Lesch KP, Lanfumey L, Steinbusch HW, Kenis G. Epigenetic regulation of the BDNF gene: implications for psychiatric disorders. Mol Psychiatry. 2012;17(6):584-96.

30. Egan MF, Kojima M, Callicott JH, Goldberg TE, Kolachana BS, Bertolino A, Zaitsev E, Gold B, Goldman D, Dean M, et al. The BDNF val66met polymorphism affects activity-dependent secretion of BDNF and human memory and hippocampal function. Cell. 2003;112(2):257-69.

31. Zai CC, Manchia M, De Luca V, Tiwari AK, Chowdhury NI, Zai GC, Tong RP, Yilmaz Z, Shaikh SA, Strauss J, et al. The brain-derived neurotrophic factor gene in suicidal behaviour: a meta-analysis. Int J Neuropsychopharmacol. 2012;15(8):1037-42.

32. Hao R, Qi Y, Hou DN, Ji YY, Zheng CY, Li CY, Yung WH, Lu B, Huang Y. BDNF val66met polymorphism impairs Hippocampal long-term depression by down-regulation of 5-HT3 receptors. Front Cell Neurosci. 2017;11:306.

33. Dincheva I, Yang J, Li A, Marinic T, Freilingsdorf H, Huang C, Casey BJ, Hempstead B, Glatt CE, Lee FS, et al. Effect of Early-Life Fluoxetine on Anxiety-Like Behaviors in BDNF Val66Met Mice. Am J Psychiatry. 2017; 174(12):1203-13
34. Schosser A, Carlberg L, Calati R, Serretti A, Massat I, Spindelegger C, Linotte S, Mendlewicz J, Souery D, Zohar J, et al. The impact of BDNF polymorphisms on Suicidality in treatment-resistant major depressive disorder: a European multicenter study. Int J Neuropsychopharmacol. 2017;20(10):782-7.

35. Krueger F, Pardini M, Huey ED, Raymont V, Solomon J, Lipsky RH, Hodgkinson CA Goldman D, Grafman J. The role of the Met66 brain-derived neurotrophic factor allele in the recovery of executive functioning after combat-related traumatic brain injury. J. Neurosci. Off. J. Soc. Neurosci. 2011;31(2):598-606.

36. McAllister TW, Tyler AL, Flashman LA, Rhodes $\mathrm{CH}$, McDonald BC, Saykin AJ, Tosteson TD, Tsongalis GJ, Moore JH. Polymorphisms in the brain-derived neurotrophic factor gene influence memory and processing speed one month after brain injury. J Neurotrauma. 2012;29(6):1111-8.

37. Verhagen $M$, van der Meij $A$, van Deurzen PA, Janzing JG, Arias-Vasquez $A$, Buitelaar JK, Franke B. Meta-analysis of the BDNF Val66Met polymorphism in major depressive disorder: effects of gender and ethnicity. Mol Psychiatry. 2010;15(3):260-71.

38. Advani T, Koek W, Hensler JG. Gender differences in the enhanced vulnerability of BDNF+/- mice to mild stress. Int J Neuropsychopharmacol. 2009:12(5):583-8.

39. Autry AE, Adachi M, Cheng P, Monteggia LM. Gender-specific impact of brain-derived neurotrophic factor signaling on stress-induced depressionlike behavior. Biol Psychiatry. 2009;66(1):84-90.

40. Chan CB, Ye K. Sex differences in brain-derived neurotrophic factor signaling and functions. J Neurosci Res. 2017;95(1-2):328-35.

41. Beck AT, Epstein N, Brown G, Steer RA. An inventory for measuring clinical anxiety: psychometric properties. J Consult Clin Psychol. 1988;56(6):893-7.

42. Beck AT, Ward CH, Mendelson M, Mock J, Erbaugh J. An inventory for measuring depression. Arch Gen Psychiatry. 1961;4:561-71.

43. Smarr KL, Keefer AL. Measures of depression and depressive symptoms: Beck depression inventory-II (BDI-II), Center for Epidemiologic Studies Depression Scale (CES-D), geriatric depression scale (GDS), hospital anxiety and depression scale (HADS), and patient health Questionnaire-9 (PHQ-9). Arthritis Care Res. 2011;63(Suppl 11):S454-66.

44. Wei YC, Wang SR, XH X. Sex differences in brain-derived neurotrophic factor signaling: functions and implications. J Neurosci Res. 2017;95(1-2):336-44.

45. Sohrabji F, Miranda RC, Toran-Allerand CD. Identification of a putative estrogen response element in the gene encoding brain-derived neurotrophic factor. Proc Natl Acad Sci U S A. 1995;92(24):11110-4.

46. Moreno-Piovano GS, Varayoud J, Luque EH, Ramos JG. Long-term ovariectomy increases BDNF gene methylation status in mouse hippocampus. J Steroid Biochem Mol Biol. 2014;144 Pt B:243-52.

47. Barbey AK, Colom R, Paul E, Forbes C, Krueger F, Goldman D, Grafman J. Preservation of general intelligence following traumatic brain injury: contributions of the Met66 brain-derived neurotrophic factor. PLoS One. 2014;9(2):e88733.

48. Duman $\mathrm{CH}$, Schlesinger $\mathrm{L}$, Kodama M, Russell DS, Duman RS. A role for MAP kinase signaling in behavioral models of depression and antidepressant treatment. Biol Psychiatry. 2007;61(5):661-70.

49. Martinowich $\mathrm{K}$, Manji H, Lu B. New insights into BDNF function in depression and anxiety. Nat Neurosci. 2007;10(9):1089-93.

50. Gatt JM, Nemeroff CB, Dobson-Stone C, Paul RH, Bryant RA, Schofield PR, Gordon E, Kemp AH, Williams LM. Interactions between BDNF Val66Met polymorphism and early life stress predict brain and arousal pathways to syndromal depression and anxiety. Mol Psychiatry. 2009;14(7):681-95.

51. Elzinga BM, Molendijk ML, Oude Voshaar RC, Bus BA, Prickaerts J, Spinhoven P, Penninx BJ. The impact of childhood abuse and recent stress on serum brain-derived neurotrophic factor and the moderating role of BDNF Val66Met. Psychopharmacology. 2011;214(1):319-28.

52. Kaufman J, Yang BZ, Douglas-Palumberi H, Grasso D, Lipschitz D, Houshyar S, Krystal JH, Gelernter J. Brain-derived neurotrophic factor-5-HTTLPR gene interactions and environmental modifiers of depression in children. Biol Psychiatry. 2006;59(8):673-80.

53. Kim JM, Stewart R, Kim SW, Yang SJ, Shin IS, Kim YH, Yoon JS. Interactions between life stressors and susceptibility genes (5-HTTLPR and BDNF) on depression in Korean elders. Biol Psychiatry. 2007;62(5):423-8. 